\title{
Remobilization of Tol2 transposons in Xenopus tropicalis
}

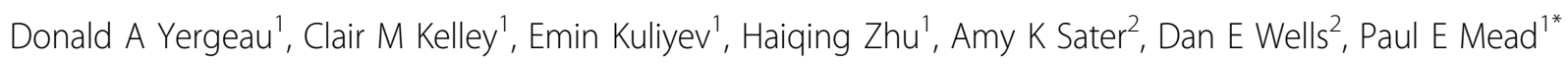

\begin{abstract}
Background: The Class II DNA transposons are mobile genetic elements that move DNA sequence from one position in the genome to another. We have previously demonstrated that the naturally occurring To/2 element from Oryzias latipes efficiently integrates its corresponding non-autonomous transposable element into the genome of the diploid frog, Xenopus tropicalis. Tol2 transposons are stable in the frog genome and are transmitted to the offspring at the expected Mendelian frequency.

Results: To test whether Tol2 transposons integrated in the Xenopus tropicalis genome are substrates for remobilization, we injected in vitro transcribed To/2 mRNA into one-cell embryos harbouring a single copy of a To/2 transposon. Integration site analysis of injected embryos from two founder lines showed at least one somatic remobilization event per embryo. We also demonstrate that the remobilized transposons are transmitted through the germline and re-integration can result in the generation of novel GFP expression patterns in the developing tadpole. Although the parental line contained a single To/2 transposon, the resulting remobilized tadpoles frequently inherit multiple copies of the transposon. This is likely to be due to the Tol2 transposase acting in discrete blastomeres of the developing injected embryo during the cell cycle after DNA synthesis but prior to mitosis.

Conclusions: In this study, we demonstrate that single copy To/2 transposons integrated into the Xenopus tropicalis genome are effective substrates for excision and random re-integration and that the remobilized transposons are transmitted through the germline. This is an important step in the development of 'transposon hopping' strategies for insertional mutagenesis, gene trap and enhancer trap screens in this highly tractable developmental model organism.
\end{abstract}

\section{Background}

Transposons are naturally occurring mobile genetic elements and have been used as tools to experimentally modify the genomes of a wide range of model organisms. Used extensively in insects and plants for decades, recent advances in transposon-based technologies have expanded their use to vertebrate systems. DNA-based 'cut-and-paste' transposon systems have been adapted to provide efficient transgenesis tools that can stably integrate an exogenous cargo into the genome without incorporation of plasmid vector sequences. Sleeping Beauty (SB), a member of the Tc1/mariner family of transposable elements, was molecularly reconstructed from an ancient inactive element found in Salmonoid

\footnotetext{
* Correspondence: paul.mead@stjude.org

'Department of Pathology, St. Jude Children's Research Hospital, 262 Danny Thomas Place, Memphis, TN 38105, USA
}

fishes [1]. $S B$ has been used extensively in the mouse for cancer gene discovery [2-5], in Xenopus for transgenesis [6-8], and zebrafish for gene and enhancer trap screens [9-13]. The piggyBac transposon system from the cabbage looper moth [14] has been shown to efficiently insert into vertebrate [15] and invertebrate genomes [16-20]. Most recently, piggyBac was used to non-virally integrate key developmental genes to reprogram induced pluripotent stem (iPS) cell lines [21,22].

Isolated from the teleost medaka (Oryzias latipes) as the first functional vertebrate autonomous transposase [23], Tol2 is a member of the $h A T$ family (hobo from Drosophila, Ac from maize, and Tam3 from snapdragon) of transposable elements. Genetic manipulation of the Tol2 system has produced a non-autonomous element suitable for transgenesis applications. The non-autonomous Tol2 element requires active Tol2 transposase to 
be supplied in trans for integration of cargo DNA flanked by the Tol2 transposon terminal end repeats into the genome [24-26]. Tol2 acts as a 'cut-and-paste' transposase integrating its transposable element randomly throughout the genome and creates a characteristic eight (8) base pair target site duplication (TSD) of host genomic DNA flanking the integration site. Tol2 has been successfully used for integration of exogenous DNA into zebrafish for transgenesis $[27,28]$ and enhancer and gene trap strategies [29-32]. Previously, we demonstrated that Tol2 effectively integrates a GFP reporter construct driven by the ubiquitous EF-1 $\alpha$ promoter (Tol2XIG) into the amphibian model organism Xenopus tropicalis [33]. The Tol2 transposable element is stable in the Xenopus tropicalis genome and is transmitted to progeny at expected Mendelian ratios following the $F_{1}$ generation.

Once integrated into the genome, Tol2 non-autonomous transposons can act as substrates for remobilization only in the presence of active Tol2 transposase [34]. Methods to re-express the Tol2 transposase in vertebrates include injection of the Tol2 transposase mRNA directly into one-cell embryos carrying a Tol2 transposon and by the development of Tol2 transposase-expressing transgenic lines that can be outcrossed with Tol2 transposon substrate lines. The transposase injectionbased method is time-consuming due to the injection of the transposase mRNA directly into individual embryos whereas the breeding-based double-transgenic strategy is potentially more efficient for large-scale remobilization screens. In the zebrafish, resident Tol2 transposons can be remobilized to novel loci in the presence of the Tol2 transposase $[29,35]$. Both injection and in vivo expression of the Tol2 transposase in Tol2 transposonhaboring animals resulted in novel re-integration events throughout the zebrafish genome [35]. Remobilized Tol2 transposons in the zebrafish can result in novel tissuerestricted GFP expression profiles that can be used for the study of organogenesis [29,36-38]. A recent report from the Largaespada laboratory also demonstrates that Tol2 transposons can be remobilized in the germline of mice [39].

To determine whether re-expression of the Tol2 transposase can remobilize a transposon present in the Xenopus tropicalis genome, we injected Tol2 transposase mRNA into one-cell embryos harvested from transgenic frogs heterozygous for a single Tol2 transposon and analyzed the developing tadpoles for remobilization. We identified at least one novel integration site in each embryo injected with the Tol2 transposase mRNA. This confirmed that Tol2 transposons resident in the frog genome are effective substrates for remobilization strategies. To test whether these remobilization events can be transmitted to progeny, we raised Tol2 transposase injected tadpoles to adulthood and outcrossed the 'remobilized frogs' to wild type animals. Progeny from one animal, $12 \mathrm{M} 2$ \% 5 , exhibited a GFP expression pattern not seen in the Tol2 12M2 transposon line used for injection. Analysis of progeny from $12 \mathrm{M} 2 \% 5$ showed germ-line transmission of four novel integration events and that these four integration sites can be independently segregated by outcross. Several of these novel integration sites are located within genes suggesting that Tol 2 can potentially target genes for insertional mutagenesis strategies. In addition, we show that the parental Tol2 integration site is frequently maintained in remobilized progeny suggesting that Tol2, like other $h A T$ family members [40-42], catalyzes transposition during cell division. Overall, our study provides the first evidence that Tol2 can remobilize its cognate transposon to novel loci in the genome of Xenopus tropicalis and thus provides a powerful genetic tool to manipulate the frog genome for gene and enhancer trapping and insertional mutagenesis.

\section{Results}

Integration of Tol2XIG transposons at discrete loci result in different GFP expression patterns

We previously reported the efficient integration and germline transmission of a Tol2 GFP reporter transposon construct into the genome of the frog Xenopus tropicalis [33]. In our previous studies, we showed that Tol2 transposons are stable in the genome and are transmitted at Mendelian ratios following the $F_{1}$ generation. Preliminary analysis of line $12 \mathrm{M}$ had indicated that this founder contained independently-segregating Tol2XIG transposon alleles [33]. Sequential outcross of the $12 \mathrm{M}$ line resulted in segregation of these alleles to reveal four distinct GFP expression patterns corresponding to four unique integration events in the $12 \mathrm{M}$ founder (see [Additional file 1: Supplemental data] and [Additional file 2: Supplemental fig. S1] and [Additional file 3: Supplemental fig. S2] for details).

\section{Injection-mediated Tol2 transposon remobilization in}

\section{Xenopus tropicalis}

To test the ability of a resident Tol2 transposon to be remobilized in vivo, we performed a pilot injectionbased screen using $F_{2}$ progeny derived from two founder lines, $10 \mathrm{M}$ and $12 \mathrm{M}$ [33]. To simplify the subsequent analysis, the $F_{1}$ transgenic parents used for this experiment each harboured a single transposon integration event. Xenopus tropicalis embryos at the onecell stage were injected with $500 \mathrm{pg}$ of in vitro transcribed Tol2 transposase mRNA and genomic DNA was harvested from individual tadpoles at stage 40 (Figure 1a). EPTS LM-PCR was performed to identify the genomic sequence flanking the 5' end of the Tol2 transposon arm. The results of somatic remobilization 
of the Tol2 transposon in two different founder lines, $10 \mathrm{M}$ and 12M2 ( $h b r)$ are shown in Figure 1b. Eighteen individual stage 40 tadpoles were analyzed by EPTS LM-PCR [43] and 100\% (18/18) of the embryos had at least one new integration site and several tadpoles had multiple, novel integration events. For example, in embryo 10M-1, four integration sites were identified that were different from the parental scaffold 246 integration site and each new integration had a unique 8 base pair (bp) target site duplication (TSD). In addition, re-integration of the Tol2 transposon was observed in individual embryos on the same scaffold as the parental integration event. Genomic DNA prepared from embryos 10M-3 and 12M-2 harboured remobilization events of the Tol2 transposon on the same scaffold as the parental locus (the 10M line has an integration on scaffold 246 that maps to the long arm of chromosome 8 (Figure $2 \mathrm{~b}$ ); and the $12 \mathrm{M} \mathrm{F}_{1}$ female frog (12M2) used in this experiment harbours an integration on scaffold 98 (the $h b r$ allele)). This indicates that Tol2, like other DNA 'cut-and-paste' transposases, can catalyze remobilization events that re-integrate near the site of excision, a phenomenon referred to as 'local hopping'. The scaffold identity, revealed by BLASTN search of the flanking sequence with the Xenopus tropicalis genome assembly v4.1, was "mapped" to the chromosomal assignment by comparing the scaffold number with the list of scaffolds mapped to unique linkage groups on the Xenopus tropicalis genetic map (Figure 2). We have adopted the modified Xenopus tropicalis chromosome nomenclature described by Khokha and colleagues [44]. This analysis indicated that, in addition to 'local hopping', re-integration events had occurred throughout the genome. Thus, we can conclude that expression of the Tol2 transposase by microinjection can remobilize a resident Tol2 transposon in an established founder line. Furthermore, we were able to remobilize the Tol2 transposon substrate in embryos harvested from either male or female heterozygous Tol2XIG transgenic parents.

\section{Analysis of transposase injected tadpoles for germline transmission of remobilized Tol2 transposons}

In a pilot injection-based remobilization experiment we used an $\mathrm{F}_{1}$ female, $12 \mathrm{M} 2$, that inherited the $h b r$ integration site alone, confirmed by multiple outcrosses, genomic PCR, Southern blot and GFP visualization ([Additional file 2: Supplemental Fig. S1a] and data not shown). Injected embryos from female $12 \mathrm{M} 2$ were divided into two pools, one group was harvested for somatic remobilization studies (Figure $1 \mathrm{~b}$ ) and the remaining pool was allowed to develop to adult stage. The adult 'remobilized' $12 \mathrm{M} 2 \mathrm{~F}_{2}$ frogs were outcrossed to wild type animals to determine whether the remobilized transposons are passed through the germline.

Seven GFP-positive $F_{2}$ 'remobilized' adults were successfully out-crossed to wild type frogs to test for germline transmission of remobilized Tol2 transposons (table 1). Due to the mosaic nature of transgenic founder $\left(\mathrm{P}_{0}\right)$ animals derived from the co-injection of transposon plasmid substrate and synthetic Tol2 mRNA, we anticipated that remobilization by injecting Tol2XIG transgenic embryos with Tol2 transposase mRNA would result in mosaic animals. This is due to the ability of Tol2 to catalyze remobilization events in discrete blastomeres during the early stages of development, and thus the resulting animal, and its germline, is likely to be mosaic for the parental and novel Tol2XIG transposon integration events. To examine this, we analyzed tissues from an adult remobilized animal (12M2O3) that had died following outcross. Integration site analysis was performed on genomic DNA prepared from multiple tissues to verify the mosaic nature of the injection-mediated remobilization products. Novel re-integration events were identified in discrete somatic tissues of this animal. EPTS LM-PCR confirmed at least two remobilization events in genomic DNA isolated from the right lung (scaffold 2:5750172, chromosome 9/LG 3 in the first intron of saccharopine dehydrogenase and in scaffold 486:789402, into a splice isoform of a GTPase activating Rap/Ran-GAP domainlike 1 protein). Interestingly, the integration site into scaffold 486 is on chromosome 5/LG 9, the same chromosome as the $h b r$ parental integration site. Analysis of progeny obtained from animal $12 \mathrm{M} 2$ 우 3 show no germline remobilization (data not shown). Likewise, integration site analysis of genomic DNA harvested from the left and right ovaries indicated no evidence for remobilization in the germline (data not shown). This result confirms remobilization of the resident transposon in somatic tissues, consistent with our earlier studies (see Figure 1b), but that remobilization events occurred in a blastomere leading to formation of the right lung and not in the germline.

Table 1 shows the rates of transgenesis from outcrosses of seven adult 'remobilized' frogs. As the parental frog used to generate embryos for this experiment contained a single copy of the Tol2XIG transposon, we expected $50 \%$ of the progeny to have the dominant GFP allele. The data presented in table 1 shows that the observed frequency of GFP-positive tadpoles in the outcross population frequently varied from the expected 1:1 ratio of GFP-positive and GFP-negative animals. To date, we have cloned novel integration events from one of these 'remobilized' animals, $12 \mathrm{M} 2$ \%5 (table 1, bold). 
a

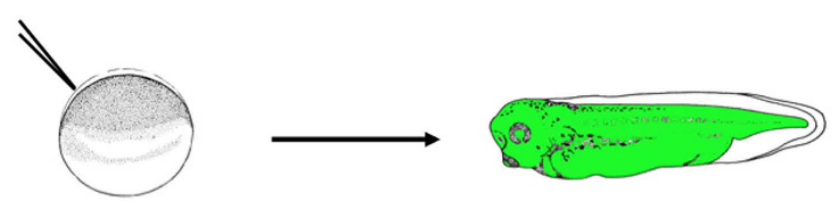

b

\begin{tabular}{|c|c|c|c|}
\hline $\begin{array}{l}\text { Tadpole } \\
\text { and } \\
\text { Clone ID }\end{array}$ & $\begin{array}{l}\text { 5' Flanking Sequence (uppercase) } \\
\text { Target site duplication (underlined) } \\
\text { Tol2 sequence (lowercase italicized) }\end{array}$ & $\begin{array}{l}\text { JGI } \\
\text { Scaffold } \\
\text { Number } \\
\text { (ver 4.1) }\end{array}$ & $\begin{array}{c}\text { Flanking } \\
\text { Gene }\end{array}$ \\
\hline F1 10M & . .TCTGTTGTACCTGGAACCCCGAAATcagaggtgta. . & 246 & WD protein 21 \\
\hline $10 \mathrm{M}-1-1$ & . . AATGTGCATTTGTGGGGCTGTGTGTcagaggtgta. . & 117 & TMEM28 \\
\hline $10 \mathrm{M}-1-2$ & . .TCTAAATAACTCTCCCCCTGGTGCCcagaggtgta.. & 376 & TXNIP \\
\hline $10 \mathrm{M}-1-3$ & .. TGCTTCCTATTCATTTTACTGGAACcagaggtgta.. & 68 & KCNK7 \\
\hline $10 M-1-4$ & ... CACCCGGGTGAAAAATCGATGGGCCCagaggtgta. . & n.d. & - \\
\hline $10 \mathrm{M}-2-1$ & .. ATACTTTGCAGCATAGTGTTACCGCCagaggtgta.. & 22 & CRALBP \\
\hline $10 \mathrm{M}-3-1$ & . ATTGCAAACAAGACTATACATTACC cagaggtgta.. & 246 & WD protein 21 \\
\hline $10 \mathrm{M}-3-2$ & ..AGACAGCTTGAGTATAGTGGGCGATcagaggtgta.. & 68 & Pla2gb4b \\
\hline $12 \mathrm{M}^{\text {hbr }} q$ & ..GTGCACTACCCCTCAGACACAGAGGcagaggtgta.. & 98 & PLEKHG1 \\
\hline $12 \mathrm{M} 2-1-1$ & ..GCCTACCAGATGCCTATСTCTATTAcagaggtgta.. & 174 & c16orf73 \\
\hline $12 \mathrm{M} 2-1-2$ & . ACCAGAAGCAGTGGATACCTACCAACagaggtgta.. & 150 & OR5M9 \\
\hline $12 \mathrm{M} 2-2-1$ & .. ATGTAAGATATGTATGTGCTGATTCcagaggtgta.. & 98 & PLEKHG1 \\
\hline
\end{tabular}

Figure 1 Somatic remobilization of a single copy Tol2 transposon in Xenopus tropicalis. (a) Schematic of the micro-injection remobilization strategy. Embryos were injected with synthetic Tol2 transposase mRNA at the one-cell stage and allowed to develop to swimming tadpole stage before genomic DNA was harvested for analysis of the integration sites by EPTS LM-PCR. (b) Sequence of the To/2 integration sites identified in the 'remobilized' tadpoles. Two independent single transposon integration sites (10M and 12M) were used to demonstrate somatic

remobilization of Tol2 transposons in Xenopus tropicalis. The parental integration sites are shown in bold. Examples of novel re-integration sites, indicating remobilization of the parental transposon, are listed below the parental site and are labelled to identify the tadpole and clone number (for example, 10M-tadpole number-clone number). Multiple remobilization events could be identified in individual tadpoles, tadpole 10M-1 had four novel integration events, suggesting that multiple independent remobilizations had occurred in discrete blastomeres during early development. All tadpoles analyzed $(18 / 18=100 \%)$ had at least one novel re-integration event. The parental transposon could be remobilized from either male or female Tol2XIG $F_{1}$ transgenic donor animals. The genomic sequence flanking the $5^{\prime}$-end of the transposon is shown in capital letters and the eight base pair target site duplication (TSD) is underlined. The transposon sequence in depicted by lower case italics text. The transposon flanking sequences were compared to the Xenopus tropicalis genome sequence (JGI assembly v4.1) to identify the scaffold identity of the integration site and to identify flanking genes; the gene nearest to the transposition site is listed in the table.

\section{Characterization of $F_{1}$ progeny from remobilized founder $12 \mathrm{M} 2$ O 5}

Visual examination of all offspring derived from the outcross of the 'remobilized' 12M2 adults showed that most of the progeny have the same expression pattern of GFP as the $h b r$ founder (Additional file 2; Supplemental fig. $\mathrm{S} 1 \mathrm{a}]$. One adult animal, $12 \mathrm{M} 2 \mathrm{O} 5$, produced progeny with a GFP expression pattern different from its parent. Approximately 4.7\% (39 of 828) of the progeny from the initial outcross of $12 \mathrm{M} 2$ 5 had GFP expression visible in the kidneys (Figure 3a, white arrow) compared to
GFP positive siblings without expression in the kidney (Figure 3a white arrow head). Approximately 49\% (406 of 828 ) of the $12 \mathrm{M} 2$ 5 outcross was GFP-positive but lacked reporter expression in the kidney. GFP expression in the kidney was not observed in other lines derived from founder $12 \mathrm{M}(\mathrm{hbr}, \mathrm{slp}, \mathrm{grb}$ and $c h s)$. Outcross of the 'donor' female 12M2 with a wild type Xenopus tropicalis male produced embryos containing only the $h b r$ locus with no GFP expression within the kidney (Figure 3a, left embryo). The visual examination was confirmed by PCR and Southern analyses and showed 
a

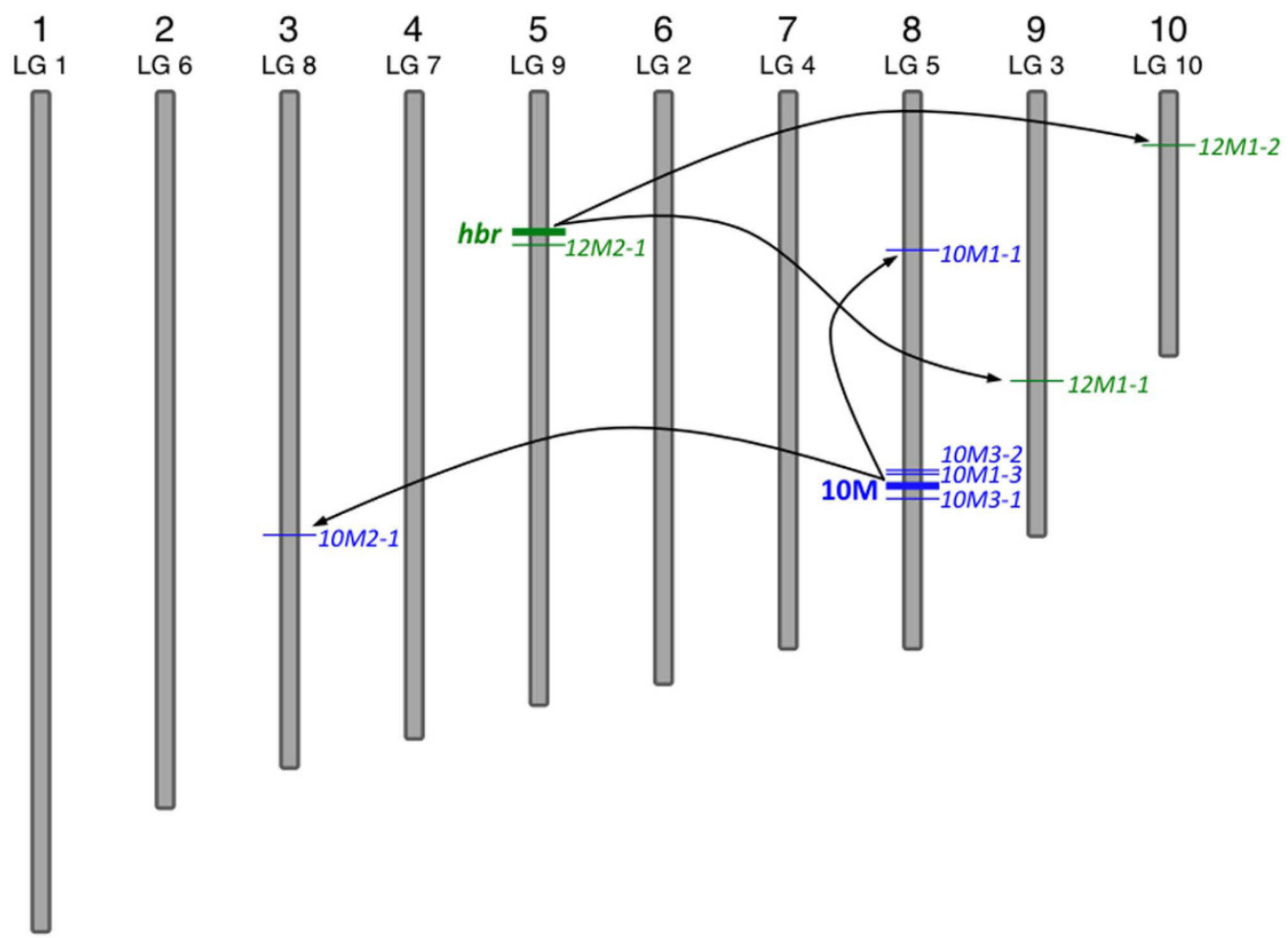

b

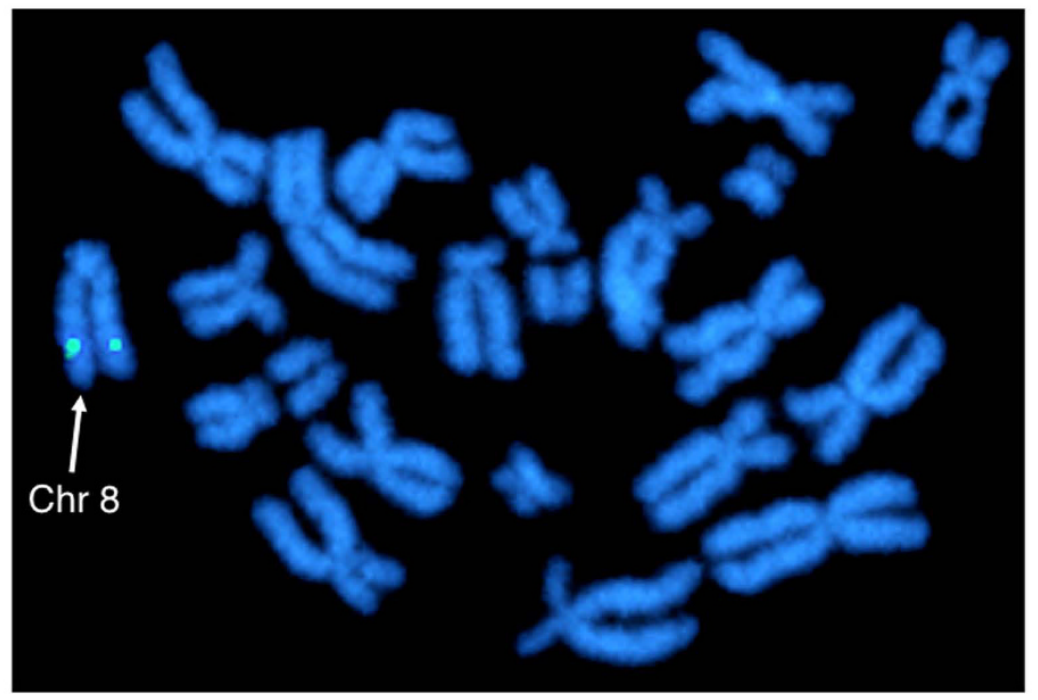

Figure 2 Chromosomal location of Tol2 transposon insertions in the Xenopus tropicalis genome. (a) Schematic representation of Xenopus tropicalis chromosomes and the relative location of the Tol2 integration sites (not to scale). Chromosomal assignments were predicted using the scaffold identity revealed by comparison of the transposon flanking sequence with the Xenopus tropicalis genome sequence (JGI v4.1 assembly). The position of the Tol2 integration on each chromosome was estimated from the map position of the corresponding scaffold. The parental integration sites (10M and $12 \mathrm{M}(\mathrm{hbr}))$ used for somatic remobilization are depicted by the thick lines and are labeled on the left side of the chromosome. Examples of remobilized somatic transposition events listed in Figure $1 \mathrm{~b}$ are labelled on the right hand side of the chromosome. Mapping the integration sites provided evidence for both 'local hopping' and random re-integration throughout the genome. (b) Fluorescent in situ hybridization (FISH) analysis of the 10M line confirms the location of the Tol2XIG transposon on the long arm of chromosome 8 (linkage group 5). Metaphase spreads prepared from heterozygous $10 \mathrm{M}$ tadpoles were hybridized with a digoxigenin-labeled GFP probe and counterstained with DAPI. 
Table 1 Analysis of outcrossed remobilization lines in Xenopus tropicalis

\begin{tabular}{|c|c|c|c|c|c|c|}
\hline Remobilized Frog & GFP + & GFP - & Total & $\% G F P+$ & \%GFP - & $\chi^{2}(d f=1)$ \\
\hline 12M20"1 & 1477 & 1536 & 3013 & 49.02 & 50.98 & 1.15 \\
\hline 12M2O2 & 379 & 374 & 753 & 50.33 & 49.67 & 0.03 \\
\hline $12 \mathrm{M} 2 \mathrm{q}^{*}$ & 4361 & 3543 & 7904 & 55.17 & 44.83 & 84.7 \\
\hline $12 \mathrm{M} 296$ & 480 & 605 & 1085 & 44.24 & 55.76 & 14.4 \\
\hline $12 \mathrm{M} 2914$ & 323 & 325 & 648 & 49.85 & 50.15 & 0.01 \\
\hline $12 \mathrm{M} 2 \mathrm{q} 16$ & 2365 & 2119 & 4484 & 52.74 & 47.26 & 13.5 \\
\hline 12M2917 & 1020 & 936 & 1956 & 52.15 & 47.85 & 3.61 \\
\hline
\end{tabular}

* Four novel remobilization events have been identified in progeny from 12M2\%5 (bold).

that the 12M2 frog contained only the $h b r$ allele. We therefore concluded that the 'kidney-positive' population represented progeny containing a novel remobilization event.

Additional outcross of Xenopus tropicalis 12M2\%5 produced tadpoles with different GFP expression levels (Figure 3b). Southern blot analysis (Figure $4 \mathrm{a}$ and $4 \mathrm{~b}$ ) was performed on genomic DNA prepared from individual tadpoles and indicated the presence of novel bands due to remobilization events. We identified numerous embryos with GFP-positive Southern blot banding patterns that were different from the parental $h b r$ locus (BamHI digest for $h b r=\sim 10.5 \mathrm{~kb}$ and BglII digest for $h b r \sim 4.5 \mathrm{~kb}$ ). EPTS LM-PCR (Figure 4c) was performed on individual embryos exhibiting unique Southern blot profiles. PCR amplification of sequences flanking the Tol2XIG transposon in the tadpoles harbouring novel insertion sites confirmed that remobilization had occurred (for example, compare the ETPS LM-PCR product in the $h b r$ lane with the joh lane, Figure 4c). The EPTS LM-PCR products were cloned and sequence analysis revealed novel integration sites that differ from the parental $h b r$ allele (Figure 4d). Genomic PCR using primers designed to the corresponding scaffold sequence outside the cloned EPTS LM-PCR product confirmed the integration site and was further verified by PCR cloning the transposon-genomic flanking sequence on the other side of the Tol2XIG transgene. We have identified four independently-segregating remobilization events from 12M2 55 and named them jovan heat (joh, scaffold 512), centaure (cen, scaffold 15/chromosome 9), brut (bru, scaffold 188/chromosome 4), and follique (fol, scaffold 98/chromosome 5). Examples of the GFP expression pattern for each of these new integration sites in developing tadpoles is depicted in Figure 3b.

Integration site analysis determined that embryos that have high-levels of GFP in the pronephric kidney contained a transposon that had integrated into the genomic locus of a putative gene encoding a novel HEAT motif-containing protein (scaffold 512:565147). The HEAT motif forms repetitive helical structures common to Huntington protein, Elongation factor 3, PP2A (A subunit of protein phosphatase 2A) and Tor (target of rapamycin) [45], so we have named this Tol2 remobilization event jovan heat (joh). The integration site is 1032 base pairs downstream of exon 9 and $77 \mathrm{bp}$ upstream of exon 10 of this predicted thirteen exon gene. The joh integration event occurred in the 3'-end of a predicted HEAT motif-containing protein, however, in situ hybridization [46] with antisense RNA probes for this gene did not exhibit robust expression in the developing kidney (data not shown). The nearest flanking gene downstream of the joh integration site is HNF1ß, a gene that is highly expressed in the developing Xenopus kidney ([47] and [Additional file 4: Supplemental fig. S3]) and is a likely candidate for the gene driving the GFP expression pattern observed in joh. This data indicates that the gene closest to the transposon integration site may not be responsible for the observed GFP expression pattern as the minimal EF- $1 \alpha$ promoter in the Tol2XIG transposon may be influenced by regulatory elements of more distal flanking genes.

The second remobilization event, follique ( $f o l$ ), occurred in scaffold 98:2697817, approximately $153 \mathrm{~kb}$ away from the parental $h b r$ locus and represents a 'local hopping' event. Here, Tol2 has integrated immediately adjacent to the first exon (169 base pairs upstream of the translational start site (Figure $5 \mathrm{~b})$ ) of the predicted Xenopus tropicalis methylenetetrahydrofolate dehydrogenase (NADP + dependent) 1-like (MTHFD1L) gene. The MTHFD1L enzyme is important in folate metabolism and is required for purine synthesis during embryogenesis and rapid cell growth [48]. Polymorphisms of MTHFD1L in humans are associated with disease susceptibility and embryonic abnormalities including neural tube defects [49]. The proximity of the Tol2 integration site to the transcription start site of this mRNA suggests that this integration may be mutagenic; a hypothesis that will be tested in the future by incross of heterozygous animals bearing single Tol2XIG fol alleles.

The centaure (cen) allele results from a Tol2 remobilization into scaffold 15:1853930 within a $10 \mathrm{~kb}$ intron of the predicted centaurin- $\gamma-2$ gene locus that encodes a large multi-domain ArfGAP membrane protein that 


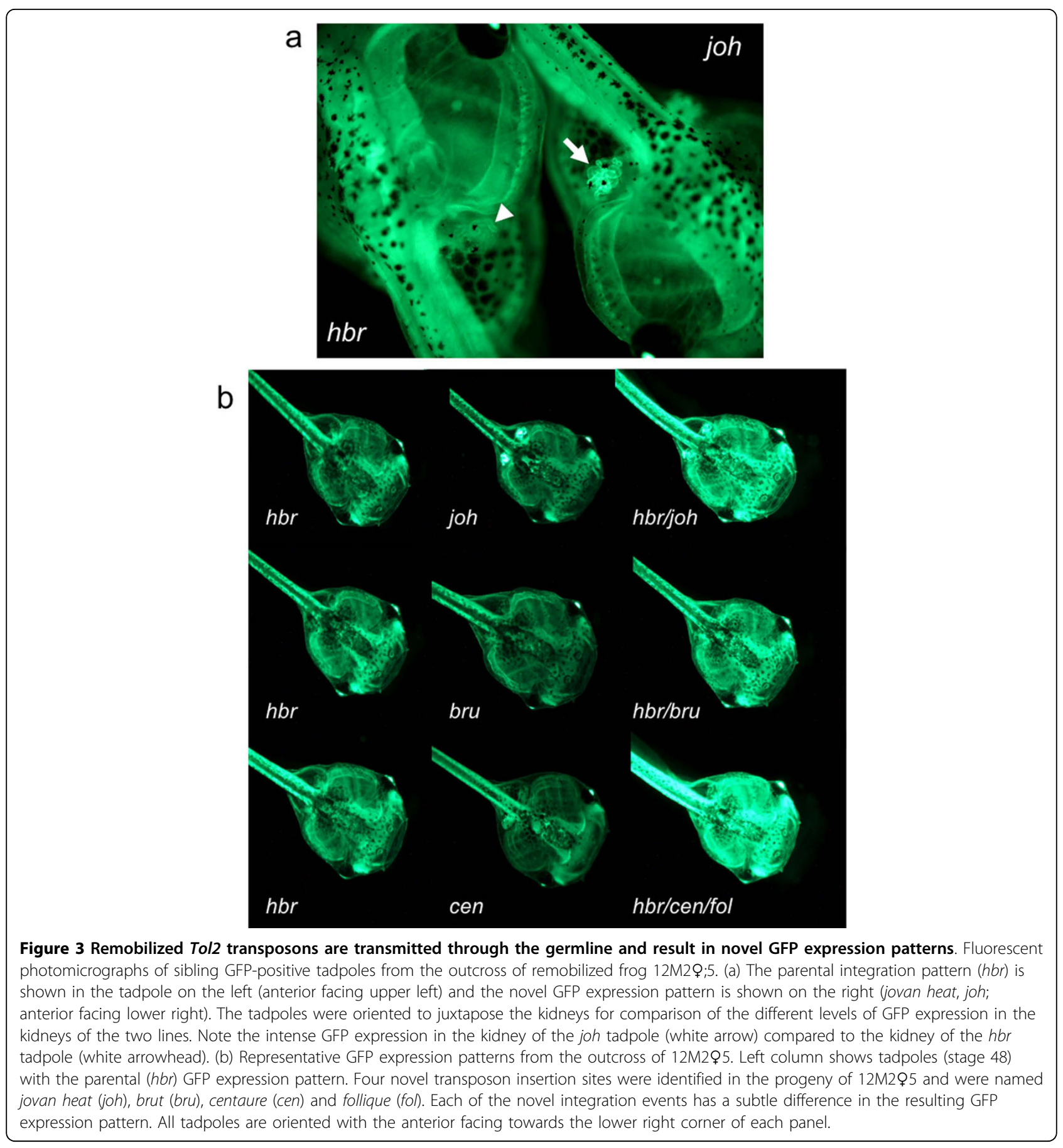

contains ankyrin repeats and a pleckstrin homology domain [50].

EPTS LM-PCR clones of the brut (bru) allele contain repetitive sequences that align with repeat elements in scaffold 188. Here, the Tol2XIG re-integration site is within the genomic locus of a predicted gene encoding a member of the TRCI (Transposon Related to CACTA I) family of transposases [51]. Analysis of the predicted amino acid sequence indicates that most of the putative
$X t$ TRCI protein shares a high degree of homology to TRCs in zebrafish, sea urchin, Drosophila, mosquito, hydra and fluke, and is completely conserved in the transposase domains.

To determine whether excision of the Tol2XIG transposon from the parental locus resulted in a footprint, that is, the modification of the endogenous locus, we performed genomic PCR of the endogenous locus with primers that flank the $h b r$ integration site on scaffold 


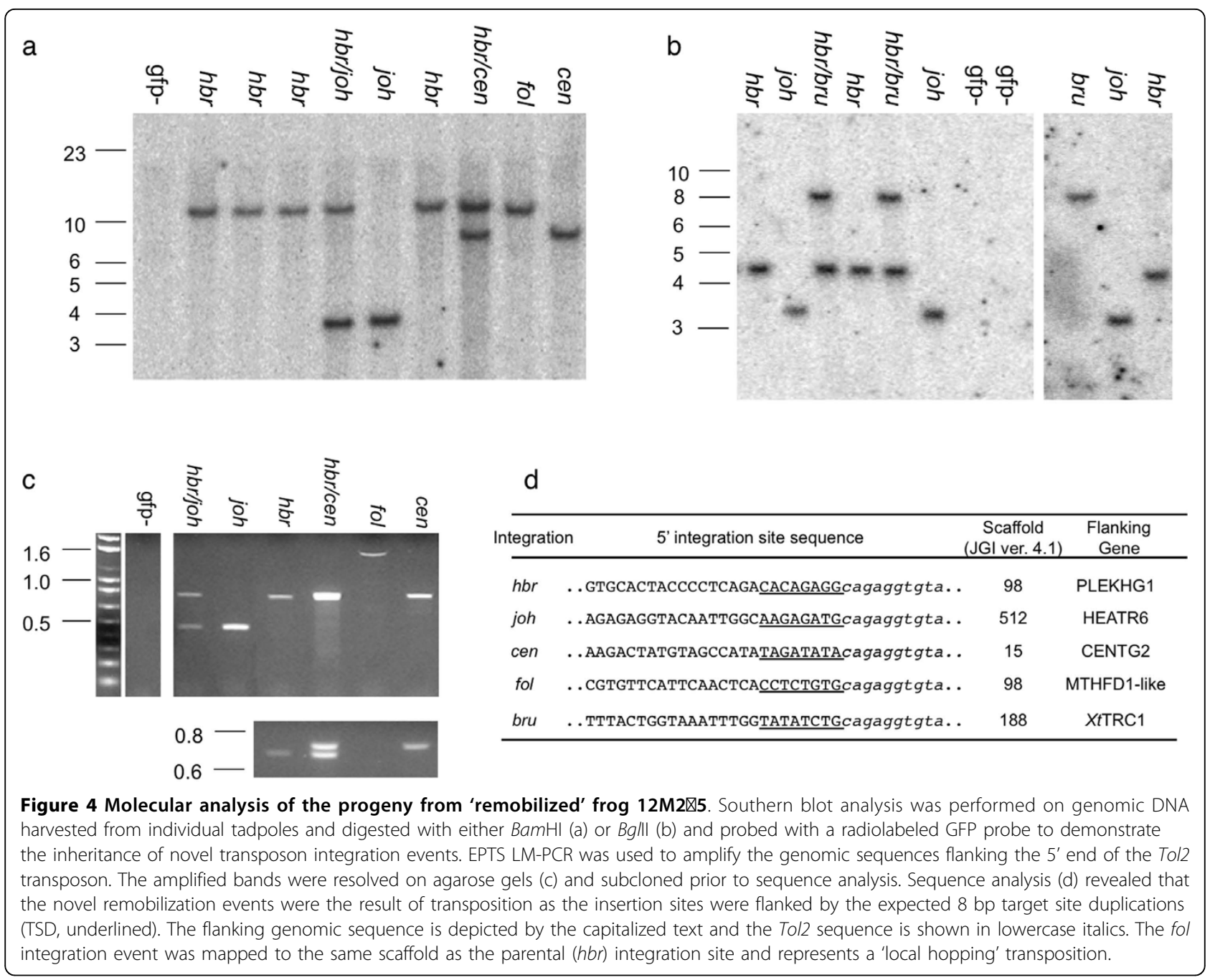

98. The sequence of the PCR products from multiple tadpoles was identical to the wild type locus indicating that the excision reaction resulted in the precise removal of the Tol2 transposon with no apparent modification of the locus (genomic DNA from six GFP-positive tadpoles, with individual or combinations of the fol, cen and joh alleles, were PCR amplified and sequenced; data not shown). We also examined genomic DNA samples from the somatic remobilization experiments and were unable to detect modifications caused by excision of the Tol2 element (genomic DNA from eight 10M remobilized tadpoles was analyzed; data not shown).

To determine the percentage of the progeny from $12 \mathrm{M} 295$ that inherit either the parental $(h b r)$ allele or the four novel remobilized alleles (joh, cen, fol and bru) we sorted embryos into GFP-positive and GFP-negative populations and then randomly selected 126 GFP-positive tadpoles for analysis. Each tadpole was photographed and genomic DNA was prepared for molecular analyses. The genotype of each animal was determined by Southern blot and verified using genomic PCR. The data from this random sampling is shown in table 2 . Approximately 78\% (98 of 126) of the GFP-positive population from outcross of $12 \mathrm{M} 295$ harbour the parental $h b r$ allele alone. The remaining 22\% (28 of 126) contained combinations of individual integration events (11 of 126 were joh only) or combination of two, or more, integrations (for example, $\mathrm{hbr} / \mathrm{cen} / \mathrm{fol}$ was found in 3 embryos out of 126). In this randomly selected sample of 126 embryos we failed to identify tadpoles containing only the fol integration site, however, this individual allele was found in other outcrosses of 12M2 5 (see Southern blot, Figure 4a, fol lane). This data suggests that $22 \%$ of GFP-positive embryos from $12 \mathrm{M} 2$ 5 contain at least one novel remobilization event. Maintenance of the joh integration site in the genome of $F_{4}$ Xenopus tropicalis embryos

Embryos from the outcross of 12M2 5 were sorted based on their GFP expression pattern and tadpoles with the kidney pattern were raised to adults for subsequent outcross 


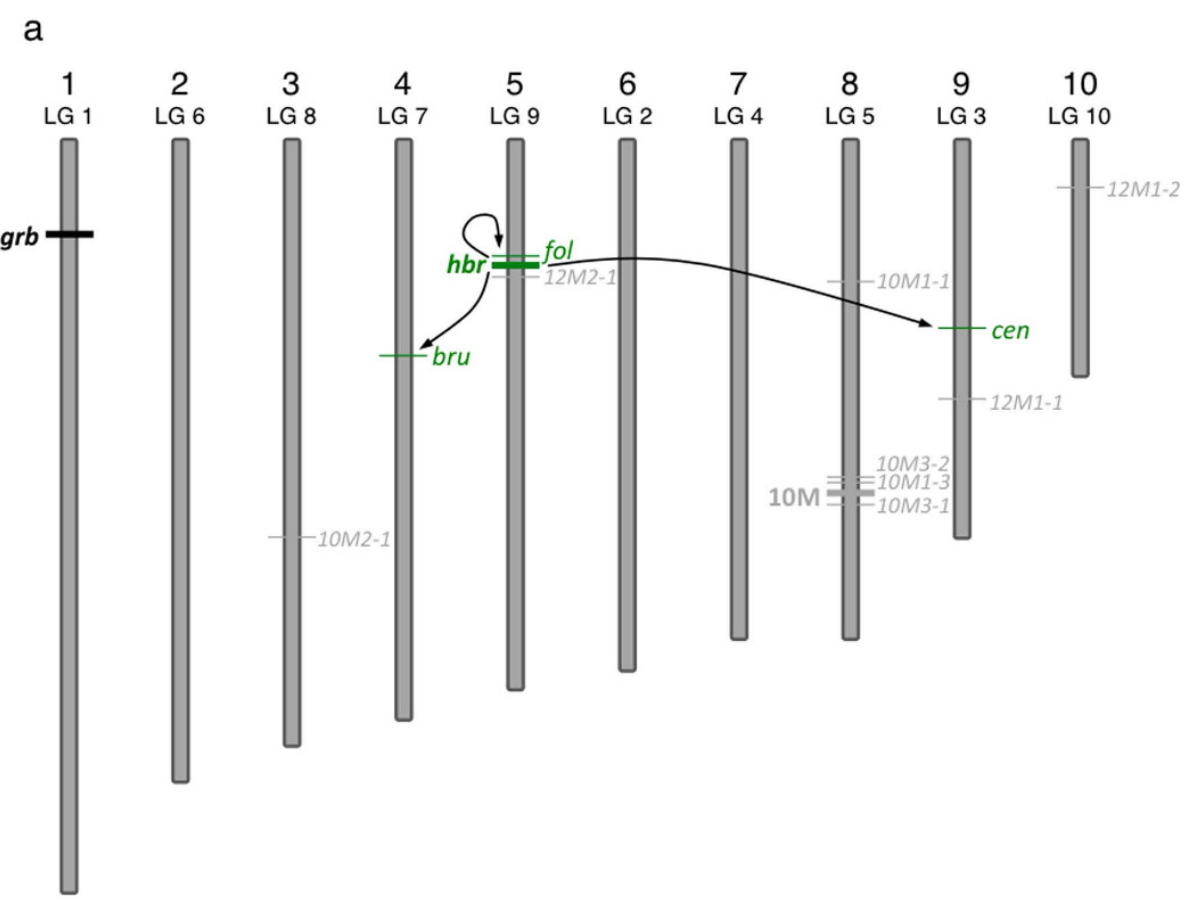

b

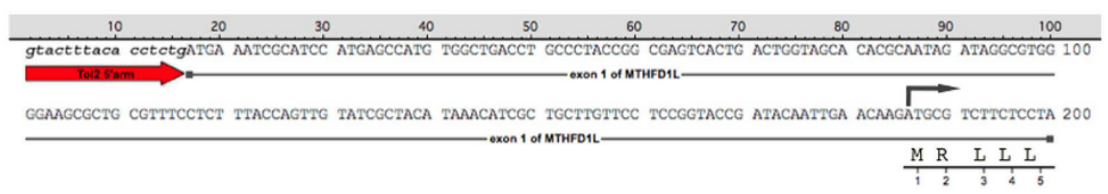

Figure 5 Chromosome map of Tol2 transposon insertions transmitted through the germline. (a) Schematic representation of Xenopus tropicalis chromosomes and the relative location of the To/2 integration sites (not to scale). Chromosomal assignments were predicted using the scaffold identity revealed by comparison of the transposon flanking sequence with the Xenopus tropicalis genome sequence (JGl v4.1 assembly). The position of the Tol2 integration on each chromosome was estimated from the map position of the corresponding scaffold. The parental integration site, $h b r$ used for the germline remobilization experiment, is depicted by the thick green line and is labeled on the left side of the chromosome. Examples of remobilized transposition events that are passed through the germline are in green and are labeled on the right hand side of the corresponding chromosome. Mapping the integration sites provided evidence for both 'local hopping' and random reintegration throughout the genome. Remobilization events are indicated by the arrows. (b) Sequence analysis of the EPTS LM-PCR product from the fol allele reveals integration of the Tol2XIG transposon at the beginning of the first exon of the MTHFD1L gene. The sequence of the $5^{\prime}$-end of Tol2XIG is in lowercase italics and represented by the red arrow. The integration event has occurred at the first nucleotide of exon 1 (uppercase text) of the MTHFD1L gene, 169 bp upstream of the translation start codon, depicted by the dark arrow above the sequence. The first five amino acids of the MTHFD1L gene are shown in single letter code below the corresponding codons.

(family tree depicted in Figure 6). To assess whether the new remobilization events are stable in the genome and that, in the absence of Tol 2 transposase activity, the novel integration events are inherited at the expected Mendelian frequencies, progeny from the outcross of two individual $\mathrm{F}_{3}$ males derived from 12M2\%5 (see Figure 6) were scored for GFP expression patterns and genomic DNA samples prepared from the $\mathrm{F}_{4}$ tadpoles were analyzed by PCR and Southern blotting. These analyses indicated that the remobilized alleles are inherited at the expected Mendelian frequencies and were stable in the genome (data not shown).

\section{Discussion}

Tol2 transposons can be remobilized in Xenopus tropicalis Our previous studies demonstrated that Tol2 is an efficient system for generating transgenic Xenopus tropicalis [33]. Here, we show that Tol2 transposons stably integrated into the frog genome are efficient substrates for remobilization following re-expression of the Tol2 transposase enzyme. Analysis of genomic DNA harvested from transgenic embryos injected at the one-cell stage with Tol2 transposase mRNA revealed that remobilization was very efficient. One hundred percent of injected 
Table 2 Unbiased analysis of 126 GFP-positive tadpoles to determine the percentage of Tol2 transposons remobilized in $12 \mathrm{M} 2 \bowtie 5$ progeny

\begin{tabular}{cccc}
\hline & Integration Site & Number of Progeny & Frequency \\
\hline Parental & hbr only & $98 / 126$ & 77.8 \\
\hline All remobilized & $28 / 126$ & 22.2 \\
\hline joh only & $11 / 126$ & 8.7 \\
\hline cen only & $2 / 126$ & 1.6 \\
\hline bru only & $3 / 126$ & 2.4 \\
\hline fol only & $0 / 126$ & $<1 \%^{*}$ \\
\hline hbr + joh & $4 / 126$ & 3.2 \\
\hline & $h b r+b r u$ & $5 / 126$ & 4.0 \\
\hline
\end{tabular}

* Embryos containing the fol integration site in isolation were observed in additional outcrosses.

transgenic animals showed novel re-integration events and we demonstrate that remobilization can be achieved in the progeny of transgenic male or female founders. Analysis of organs from an adult 'remobilized' frog indicated that the animals produced by the transposase mRNA injection technique are highly mosaic. The mosaic nature of the remobilization events is likely due to the stochastic activity of the Tol2 enzyme in the rapidly dividing Xenopus embryo. Messenger RNA encoding the transposase is injected at the one-cell stage and it is likely to take some time to accumulate sufficient Tol2 protein to catalyze the remobilization events. During this time, early cleavage stages may have occurred resulting in random remobilization events in different blastomeres of the developing embryo. The mosaic nature of the somatic remobilization events is reflected by the mosaic germline transmission of the reintegrated transposons. We demonstrated that the remobilized transposons can be passed through the germline of the injected transgenic frog and that these remobilized transposons are stable in the genome in the subsequent generations. The transmission of transposons through the germline of remobilized frogs frequently resulted in non-Mendelian inheritance of the GFP transgene in the resulting progeny (see table 1). Outcross of remobilized $F_{2}$ animals was predicted to have resulted in the expected Mendelian segregation of the dominant GFP allele, that is 50\% GFP-positive and $50 \%$ GFP-negative. Several of the outcrosses yielded transmission frequencies that were not significantly different from the expected rate of GFP-positive progeny (12M2O'1, 12M2@2 and 12M2@14). Genomic PCR analysis and Southern blot analysis indicated that only the parental $(h b r)$ allele is present in the progeny of these animals indicating that remobilization has not occurred (data not shown). In other outcrosses the observed rate of transmission of the reporter to the progeny was significantly different from the expected rate (Chi-squared analysis $\mathrm{p}<0.001$ for lines $12 \mathrm{M} 2$ \% $5,12 \mathrm{M} 2$ 6 and
$12 \mathrm{M} 20^{\prime} 16$, table 1). The variation in the expected rate of transgenesis may be due to the mosaic nature of the remobilization reaction following injection of the Tol2 transposase mRNA at the one-cell stage. For example, if the transposition reaction results in excision, but not reintegration, of the parental transposon in discrete blastomeres that will give rise to the germline, then a transmission rate lower than $50 \%$ may be anticipated. For example, progeny from founder line $12 \mathrm{M} 2 \% 6$ are $44.24 \%$ positive for GFP, suggesting a loss of GFP by excision but not reinsertion of the Tol2 transposon. It is also possible that remobilization has occurred in the germline of $12 \mathrm{M} 2$ 6 line but the novel insertion event has disrupted a genomic locus causing a loss of GFP positive embryos. Subsequent PCR and Southern blot analysis for the $12 \mathrm{M} 296$ line, however, has failed to detect any evidence for transposon re-integration in this line (data not shown). Finally, a third class of outcross embryos was identified from the 'remobilized' $12 \mathrm{M} 2$ adults. Frogs $12 \mathrm{M} 2 \% 5,12 \mathrm{M} 2 \mathrm{O}^{\prime} 16$ and $12 \mathrm{M} 2 \mathrm{O}^{\prime} 17$ each produced GFP-positive tadpoles at a rate significantly higher than that expected for the outcross of a dominant heterozygous allele. Detailed analysis of the progeny from $12 \mathrm{M} 2$ 5 demonstrated that multiple remobilization events had occurred in the germline of this frog and were passed on to the offspring. To date, we have been unable to identify novel integration sites by PCR strategies and Southern blot analysis in the progeny from founder lines $12 \mathrm{M} 20^{\prime \prime} 16$ and $12 \mathrm{M} 20^{\prime \prime} 17$ (data not shown), even though population numbers suggest Tol2 remobilization is occurring in these lines.

The germline of remobilized $\mathrm{F}_{2}$ frog $12 \mathrm{M} 2$ 5 was highly mosaic and contained four novel integration events in addition to the parental $(h b r)$ transposon. Approximately 22\% of the GFP-positive progeny from this animal contained novel remobilization events. This indicates that the germline of this frog is mosaic for the transposon insertions, and as discussed above, likely resulted from random remobilization events occurring 


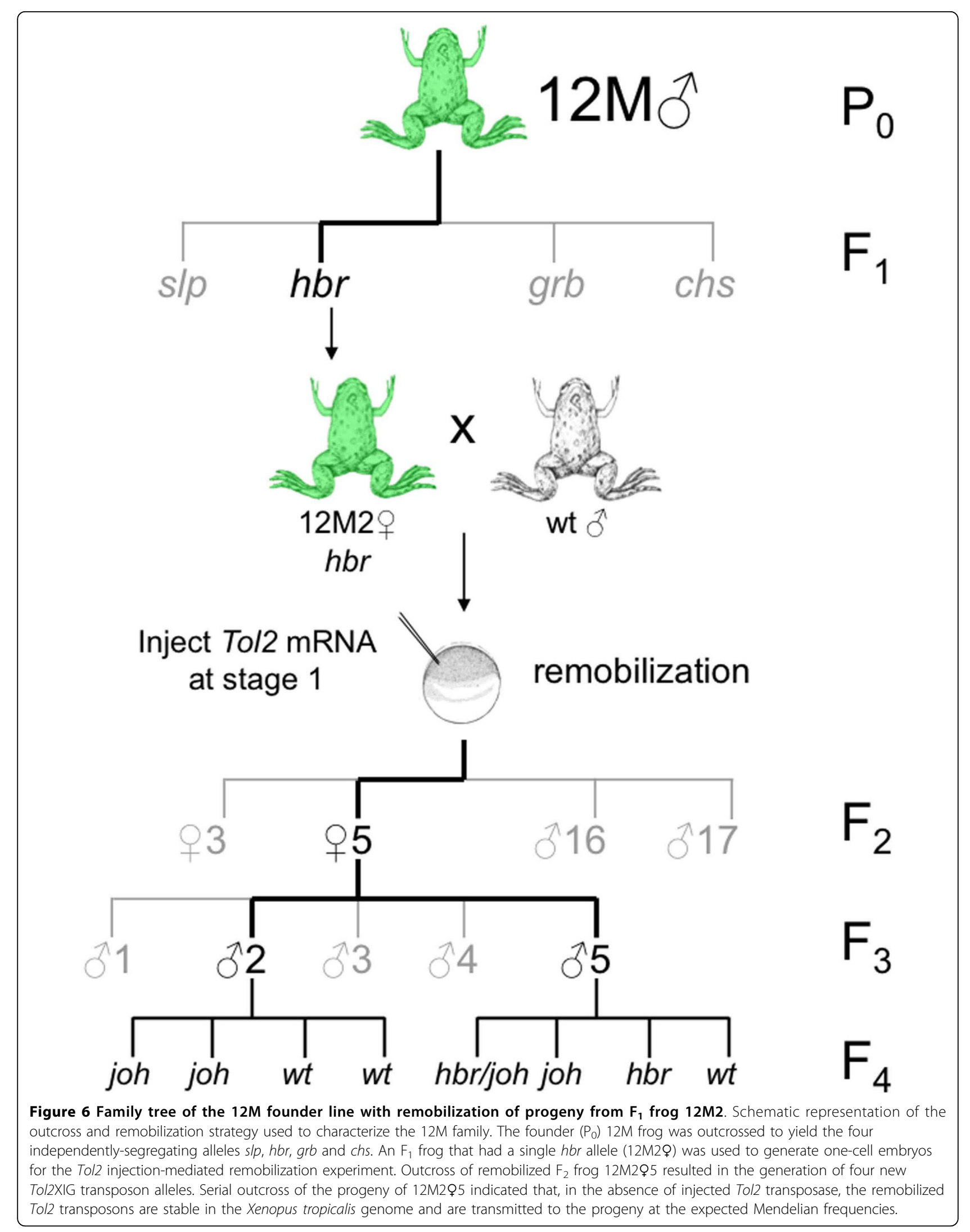


during early cleavage stages in the development of the 12M2 5 tadpole.

The different inheritance frequencies of the remobilized alleles suggest that the remobilization events occurred at different times during the development of the transposase-injected embryo $12 \mathrm{M} 2$ \% 5 . It is likely that the joh re-integration event occurred first as this is the remobilized allele most commonly seen in the outcross population. The cen allele is the next most commonly found allele and thus likely occurred after the joh remobilization event. The fol allele is commonly found with the cen allele indicating that the fol remobilization event most likely occurred in a blastomere derived from a prior cen remobilization event. As the bru allele is only seen either alone or with the parental $h b r$ allele, this suggests that this remobilization event occurred in a blastomere that was not targeted by the other remobilization events (joh, cen and $f o l$ ). This data clearly demonstrates that Tol2 transposons integrated into the Xenopus tropicalis genome are effective substrates for remobilization and the re-integration events are passed through the germline. Expression of the Tol2 transposase in early developing embryos results in random remobilization events and the germline of the resulting adult is mosaic for the parental and remobilized transposon transgenes.

The most striking feature of the progeny that resulted from this outcross was the presence of multiple alleles of the Tol2XIG transposon in the same tadpole. The $F_{1}$ frog that this line was derived from, $12 \mathrm{M} 2$, contained a single Tol2 transposon integration event, $h b r$ (see Figure 4). How does a transposase that uses a simple 'cut-and-paste' transposition mechanism result in an increase in the number of transposon alleles in individual progeny? As with the mosaic nature of the remobilized frogs, the answer likely lies in the rapid development of the early Xenopus embryo and the propensity of $h A T$ elements to mobilize during cell division [40-42]. The Xenopus embryo divides rapidly and synchronously for the first twelve cell cycles that are simple S (DNA synthesis) and M (mitosis) phases with no G (gap) phases. If Tol2 catalyzes remobilization of the resident Tol2XIG transposon in a blastomere after DNA synthesis but prior to mitosis, then, following random segregation of the sister chromatids, the resulting blastomere may inherit both the parental allele and the remobilized allele (Figure 7). Subsequent rounds of cell division and Tol2 enzymatic activity may further increase the complexity of the transposon content of an individual blastomere. If this blastomere gives rise to a germ cell, then the resulting gametes produced by this cell could contain multiple copies of the transposon transgene (Figure 7).

\section{Potential uses for Tol2 remobilization strategies in the frog}

Transposons offer efficient mechanisms for generating transgenic Xenopus. The established strategy for generating novel transgenic lines using transposon systems involves injected embryos at the one-cell stage with a cocktail containing a plasmid harbouring a transposon substrate and synthetic mRNA encoding the corresponding transposase enzyme. Micro-injection of plasmid DNA is toxic to the developing embryo and thus limits the amount of substrate that can be provided for the transposition reaction. Remobilization of transposons already integrated in the genome thus offers an attractive alternative to the co-injection approach. As illustrated in the examples shown here, the Tol2XIG transposon can act as an enhancer trap and remobilization of the transposon to novel loci can result in unique GFP expression profiles. Another potential benefit of the remobilization strategy is to take advantage of the 'local hopping' phenomenon to generate mutations in genes near the primary integration site. DNA 'cut-and-paste' transposons preferentially re-integrate at loci near the initial integration site. For example, remobilization of Sleeping Beauty transposons in the germline of mice results in approximately $50-80 \%$ of the re-integration events occurring within $5 \mathrm{cM}$ either side of the primary integration site [52-55]. The 'local hopping' phenomenon has also been observed with Tol2 in several vertebrate species. In this study, we show several examples of re-integration of the Tol2XIG transposon to the same sequence scaffold as the initial transposition event in Xenopus tropicalis. 'Local hopping' of remobilized Tol2 transposons in the zebrafish germline has recently been reported by both the Kawakami and Korzh laboratories $[35,56]$. In mice, remobilization of resident Tol2 transposons in the germline frequently results in re-integration near the donor site [39].

Small-scale micro-injection based enhancer trap screens will be performed in the frog where novel patterns are scored in the progeny of remobilized animals and the flanking sequences are cloned to reveal the nearby genes. The Soul Patch (slp) transgenic line will be ideal for remobilization studies, as excision of the transposon from this locus and re-integration at a novel site will likely change the unique GFP expression pattern observed in this line [Additional file 3: Supplemental fig. S2]. The rate-limiting step in this approach is the micro-injection technique, and future efforts will be directed at the generation of transgenic frogs that express the Tol2 transposase in the Xenopus germline. The enzyme-expressing frogs can then be crossed with substrate transposon-harbouring frogs to generate double transgenic animals that have inherited both the 

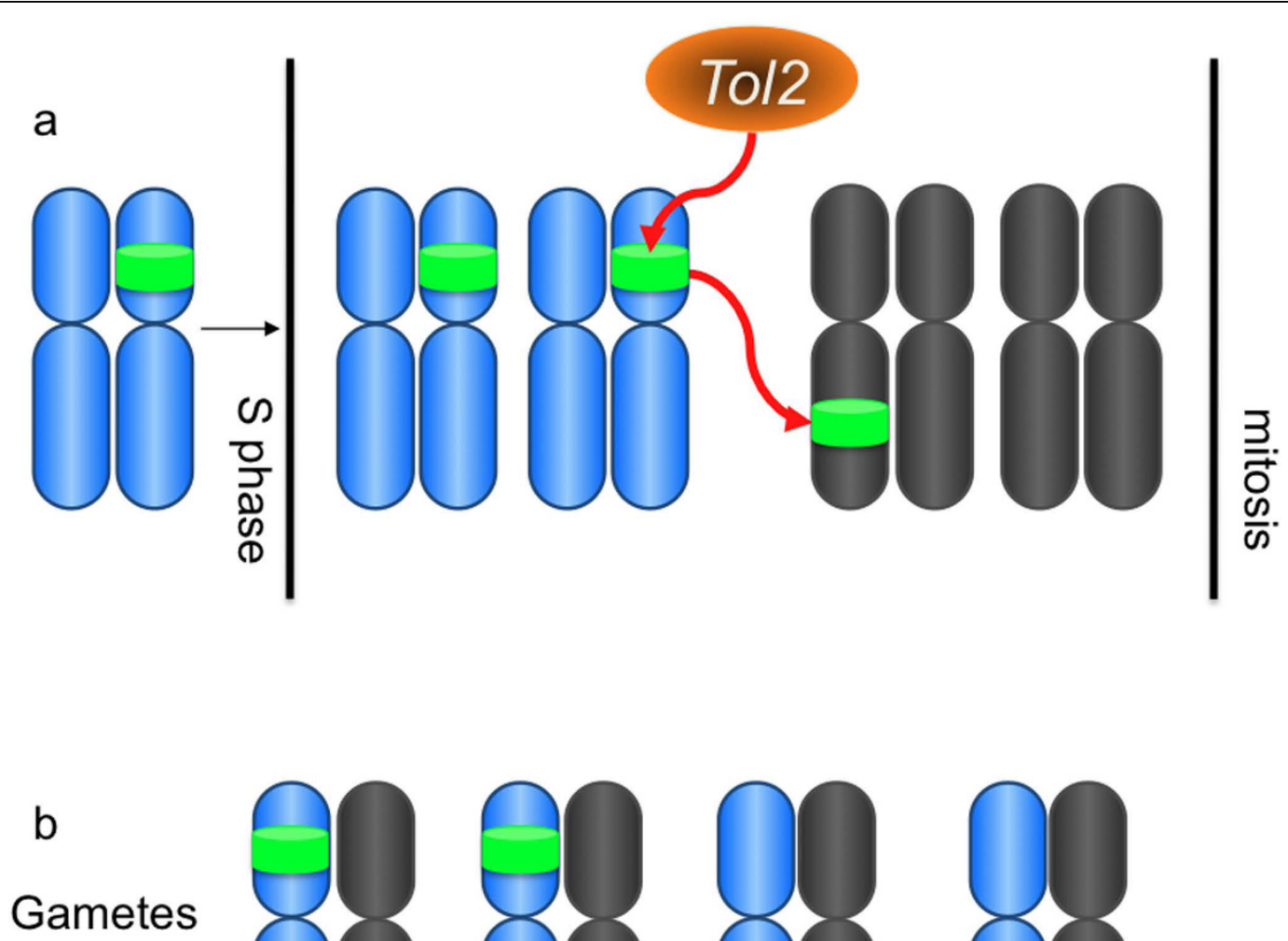

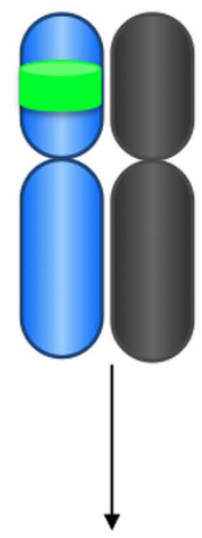

$h b r$

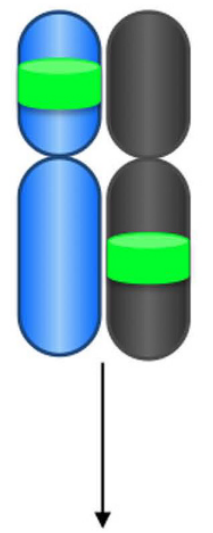

hbr/joh

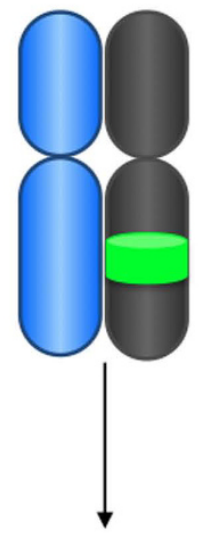

joh

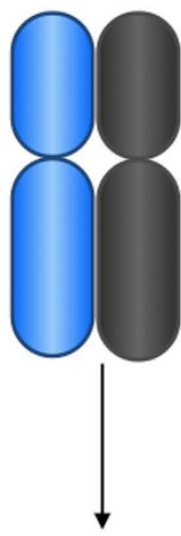

$w t$

Figure 7 Proposed mechanism for the increase in the number of transposons following injection-mediated Tol2 remobilization. Onecell embryos harvested from an outcross of 12M2, with a single transposon integration ( $h b r$ ), were injected with Tol2 mRNA. GFP-positive tadpoles were raised to adulthood and outcrossed to identify germline transmission of the remobilized transposon. Analysis of progeny from remobilized frog 12M295 indicated that many of the offspring had inherited multiple copies of the Tol2XIG transposon. The To/2 transposase uses a simple 'cut-and-paste' transposition mechanism and the apparent increase in transposon content in the progeny was unexpected. The likely explanation for the increase in number of To/2 transposons is the remobilization of the substrate following DNA replication, but prior to mitosis (reviewed in [42]), in the blastomeres in the early embryo. DNA replication (S phase) results in two copies of the Tol2 substrate in each cell and one, or both, copies can be remobilized by the injected Tol2 transposase enzyme. During mitosis the transposon alleles are randomly segregated into the daughter cells. In the example depicted in the cartoon (a), the resident To/2 transposon on the hypothetical blue chromosome is replicated during $S$ phase and one copy is remobilized by the Tol2 transposase to a new location on a hypothetical grey chromosome. If the targeted blastomere gives rise to a germ cell, then the resulting gametes may contain different combinations of the transposon alleles (b) and the resulting tadpoles may have one or both of the integration events.

enzyme and the substrate for remobilization. Outcross of these double transgenic frogs will result in progeny with novel expression patterns and remove the necessity for the micro-injection step. This double-transgenic (Tol2 substrate and Tol2 enzyme) remobilization approach has been used with success in both zebrafish and mice $[35,39]$. The advantage of pursuing this strategy in Xenopus tropicalis is the remarkable fecundity of this species, clutch sizes routinely surpass 2,000 embryos, and the longevity of the frogs, adult animals may live for twenty years or more in captivity. Combined with the exquisite embryological advantages of the Xenopus system, transposon-mediated gene and enhancer trap screening in the frog will provide an excellent combination of modern molecular genetics in a highly tractable developmental system. 


\section{Conclusions}

Tol2 transposons stably integrated into the Xenopus tropicalis genome are substrates for remobilization

Transposon transgenesis techniques offer several advantages over other techniques for manipulating the frog genome. The 'cut-and-paste' mechanism of transposase enzymes such as Tol2 results in no plasmid vector sequences being integrated along with the transgene. The integrated transposons are also efficient substrates for excision and re-integration at novel sites. This has at least two important implications. First, as described above, the integrated transposon can be remobilized to perform gene and enhancer trap screens. Second, if integration of the transposon into a locus results in a mutant phenotype, the transposon can be remobilized from that site in order to rescue the phenotype and establish a direct link between the integration event and the mutation. In this manuscript, we demonstrate that Tol2 transposons integrated in the frog genome are effective substrates for remobilization.

\section{Remobilized Tol 2 transposons are transmitted through} the germline

Micro-injection of mRNA encoding the Tol2 transposase into one-cell Tol2 transgenic embryos results in the mosaic remobilization of the transposon from the parental locus. This is likely due to random remobilization in discrete blastomeres during early embryonic development. In order for these remobilization events to be passed through the germline, the enzymatic activity must occur in blastomeres fated to contribute to the germ cells. We demonstrated that remobilized transposons are indeed transmitted through the germline of remobilized Tol2 transgenic frogs that had been injected at the one-cell stage with Tol2 mRNA. The presence of multiple Tol2 transposons in individual progeny from a 'remobilized' frog, that was derived from a founder with a single integration event, indicates that the remobilization events have occurred in the developing blastomeres after $\mathrm{S}$ phase but prior to mitosis. The remobilization events are stable in the genome and can be segregated by serial outcross of the remobilized transgenic parent. The demonstration of efficient remobilization of Tol2 transposons in the Xenopus tropicalis genome is an important step in the development of transposon-based gene and enhancer trap screens in this tractable developmental model organism.

\section{Methods}

Husbandry and micro-injection of Xenopus tropicalis

Xenopus tropicalis tadpoles were maintained at $28^{\circ} \mathrm{C}$ in static tanks and were staged according to Nieuwkoop and Faber [57]. Adult animals were housed in a recirculating aquarium at $26^{\circ} \mathrm{C}$. In vitro transcribed Tol2 transposase mRNA was prepared as previously described [33] using mMessage mMachine kits (Ambion) from a linearized pCS-TP plasmid [58]. Female Xenopus tropicalis animals were pre-primed with a 1:5 dilution of human chorionic gonadotropin (hCG) overnight and primed the day of injection with $200 \mathrm{U}$ of hCG. Fertilized eggs were obtained by natural outcross and microinjected with 500 pg of Tol 2 mRNA at the one cell stage according to previous methods [43]. Injected eggs were allowed to heal at $28^{\circ} \mathrm{C}$ and transferred to tanks for growth at $28^{\circ} \mathrm{C}$. The studies described in this manuscript were approved by the St. Jude Children's Research Hospital Animal Care and Use Committee.

\section{Southern blot hybridization}

Genomic DNA was extracted from embryos by overnight digestion at $56^{\circ} \mathrm{C}$ with $0.5 \mathrm{mg} / \mathrm{ml}$ proteinase $\mathrm{K}$, followed by phenol:chloroform extraction. Three micrograms of genomic DNA were digested overnight at $37^{\circ} \mathrm{C}$ with $15 \mathrm{U}$ of $\mathrm{Bgl \textrm {II }}$ or $\mathrm{BamHI}$ (Promega) and separated on a $0.7 \%(\mathrm{w} / \mathrm{v})$ agarose gel. Digested fragments were transferred overnight onto a Hybond $\mathrm{N}+$ nylon membrane (GE Biosciences) with 20x SSC. Blots were probed with a $\sim 700$ bp GFP fragment labeled with ${ }^{32} \mathrm{P} d C T P$ radionucleotide and the Megaprime labeling kit (GE Biosciences). After successive washes, blots were exposed onto a phosphoimager screen and processed on a Storm phosphoimager (Molecular Dynamics).

Extension primer tag selection (EPTS) linker-mediated PCR To determine the genomic integration site of transposons in Xenopus tropicalis, extension primer tag selection (EPTS) linker-mediated PCR was performed as described [43] with slight modifications. Genomic DNA samples were digested overnight with NlaIII (New England Biolabs) or AluI (New England Biolabs) and primer extension products were generated using the Tol2 biotinylated primer specific to the Tol2 5' arm sequence (5' BIO-AAA CTG GGC ATC AGC GCA ATT CAA T). One microliter $(\mu \mathrm{l})$ of each primary PCR was used as templates for nested PCR reactions. Unique nested fragments were gel-purified, ligated to the pCR4-TOPO sequencing vector (Invitrogen) and miniprep DNA was extracted using the Promega Wizard miniprep kit. DNA sequencing was performed on all isolated DNA samples and aligned using Lasergene software. Identified sequences were queried against the JGI Xenopus tropicalis genome (ver 4.1; http://genome.jgi-psf.org/Xentr4/ Xentr4.home.html) and scaffolds were assigned to chromosomes and linkage groups based on the genetic map developed at the University of Houston.

\section{Genomic PCR of identified integration sites}

Primers were designed to genomic sequences adjacent to the integration site and within the transposon arms encompassing the identified EPTS LM-PCR fragment. Primers were designed to the predicted sequence of the 
3' arm of the Tol2 transposon to further confirm the integration site. For the Handlebar ( $h b r)$ integration site, primers were designed to scaffold 98, (MJH1624, 5'GCA CAG TCT GGG CTT TGT AT) and to the 3' transposon arm of Tol2, (MJH2153, 5'-AGT AGC GTG TAC TGG CAT TA) and annealed at $55^{\circ} \mathrm{C}$. Primers were designed to the Garibaldi $(\mathrm{grb})$ integration locus in scaffold 217 (217-2, 5'-TGT TGT TGT CGT CGT TCG TT) and within the 5' arm of the Tol2 transposon (2171, 5'-CGC AAT TCA ATT GGT TTG GTA) and annealed at $52^{\circ} \mathrm{C}$. For the jovan heat (joh) integration site located in scaffold 512, primers were designed to genomic sequence outside of the EPTS LM-PCR fragment (512f1, 5'-AAT AGT TTT CCC AGT AGC AAG TTA) and to the 5' Tol2 transposon arm (512tol2R1, 5'CAA GGG AAA ATA GAA TGA AGT GAT) and annealed at $51^{\circ} \mathrm{C}$. Primers were designed for the centaure (cen) integration site on scaffold 15, (15f2 5'-TCG ATG CAA ACT ATG TCA AAG AA) and to the 5' arm of Tol2 transposon, (t3r4, 5'-TAG CGT GTA CTG GCA TTA GAT T) and annealed at $52^{\circ} \mathrm{C}$. Primers were designed to the follique $(f o l)$ integration site on scaffold 98, (n98f1, 5'-GCC CAT ATG CCT ACA GTG CCT CTA) and to the $5^{\prime}$ arm of the Tol2 transposon, (t5-f6, 5'-AAA GTA AAA ATC CCC AAA AAT AAT), and annealed at $60^{\circ} \mathrm{C}$. Approximately $200 \mathrm{ng}$ of genomic DNA was used per PCR reaction. Conditions for genomic PCR for all primer sets were as follows: $95^{\circ} \mathrm{C}$ for 15 min., followed by 35 cycles of $94^{\circ} \mathrm{C}$ for $30 \mathrm{sec}$., annealing temperature indicated above for $30 \mathrm{sec} ., 72^{\circ} \mathrm{C}$ for $45 \mathrm{sec}$. Genomic DNA was amplified using the HotStart Taq polymerase (Qiagen) and resolved on agarose gels. All products were subcloned in pGEM-Teasy (Promega) and sequenced with M13F and M13R.

\section{Microscopy and Photography of Xenopus tropicalis embryos}

Green fluorescent protein (GFP) expression was monitored using a Leica FLIII dissecting microscope. Images were obtained using a Nikon D5-5M color digital camera at the same aperture settings and exposure time in order to qualitatively assess variable GFP intensities.

\section{List of abbreviations}

BB: basihyal-basibranchial cartilage; EPTS LM-PCR: Extension Primer Tag Selection Linker Mediated Polymerase Chain Reaction; GFP: Green Fluorescent Protein; hCG: human chorionic gonadotropin; OT: outflow tract; PBT: pharyngo-branchial tract; TSD: target site duplication.

Additional file 1: Supplemental Data. Text file describing the four independently-segregating Tol2XIG integration events in founder 12M. Click here for file

[http://www.biomedcentral.com/content/supplementary/1471-213X-1011-S1.doc ]
Additional file 2: Supplemental Figure S1 - The 12M founder has four independently-segregating Tol2XIG transposons each with a unique GFP expression pattern. Outcross of the 12M founder resulted in the segregation of four independent Tol2XIG alleles and revealed unique GFP expression patterns associated with each integration event. (a) Schematic representation of the outcross of founder $12 \mathrm{M}$ to yield tadpoles with individual expression patterns. The individual patterns were named Soul Patch (s/p), Handlebar (hbr), Garibaldi (grb) and Chinstrap (chs). Tadpoles were photographed at stage 51 and the figures are oriented with anterior towards the top of the panel. The intense GFP expression in the $s / p$ embryo in the basihyal basibranchial cartilage is labelled BB. The bright GFP expression in the leading edge of the hbr tadpole is indicated by the white arrow. The white arrowhead in the chs panel points to the GFP expression in the lower jaw of the tadpole. The eye is labelled in this panel to guide the reader. (b) Southern blot analysis of $F_{1}$ tadpoles harbouring different combinations of the four transposons in founder 12M. Genomic DNA from individual tadpoles was digested with Bg/ll and the resulting Southern blot was probed with a GFP probe. (c) EPTS LM-PCR was used to clone the genomic sequences flanking the transposon insertion sites in three of the four $12 \mathrm{M}$ alleles. The genomic DNA sequence flanking the transposon is indicated by the capitalized text and the sequence of the $5^{\prime}$ end of Tol2XIG is shown in lowercase italics.

Click here for file

[http://www.biomedcentral.com/content/supplementary/1471-213X-1011-S2.tiff]

Additional file 3: Supplemental Figure S2 - GFP expression in the Soul Patch line. GFP expression profile of the Soul Patch (s/p) line derived from the Tol2XIG $12 \mathrm{M}$ founder. The EF-1 $\alpha$ promoter in the Tol2XIG construct can be influenced by local regulatory elements near the transposon insertion site to override the normal ubiquitous

expression of the GFP reporter. The s/p allele has intense GFP expression in various cartilages in the developing tadpole (Stage 51 shown). (a) s/p results in intense GFP expression in the provisionally identified basihyal basibranchial (BB) cartilage at the midline of the head. (b) Schematic representation of the tadpole head skeleton indicating the relative position of the basihyal basibranchial cartilage (adapted from Weisz, 1945 [59]). The s/p allele also results in intense GFP expression in the cartilage supporting the tentacle ( $c$ and e) and the cartilage supporting the gill arches ( $d$, white arrows). GFP expression is clearly visible in the outflow tract (OT) of the heart in s/p tadpoles ( $f$ ). Images $a, c, d$ and $f$ were taken on a fluorescent dissecting microscope and $\mathrm{e}$ is an overlay of a confocal image with the corresponding bright-field view.

Click here for file

[http://www.biomedcentral.com/content/supplementary/1471-213X-1011-S3.tiff]

Additional file 4: The jovan heat (joh) allele has a Tol2XIG transposon integrated near the HNF1 $\beta$ gene (a) Schematic representation of the Tol2XIG integration event in joh (not to scale). The transposition reaction resulted in integration of the transposon in intron 9 of a novel HEAT motif-containing gene on scaffold 512:565147. In situ hybridization with antisense RNA probes generated to the HEAT repeat CDNA indicated low-level ubiquitous expression of the HEAT motifcontaining gene that lacked robust expression in the developing kidney (data not shown). The HNF1 $\beta$ gene flanks the $3^{\prime}$ end of the HEAT motifcontaining gene and is approximately $46 \mathrm{~kb}$ from the To/2XIG transposon. (b) In situ hybridization for HNF1 $\beta$ expression during Xenopus development shows intense staining in the developing kidney [47]. Antisense RNA probes were synthesized from a Xenopus laevis HNF1 $\beta$ CDNA (IMAGE 4959359). In situ stained albino Xenopus laevis embryos shown at stages 27 and 35 (anterior is facing to the right, dorsal up). Arrows point to the developing kidney.

Click here for file

[http://www.biomedcentral.com/content/supplementary/1471-213X-1011-S4.tiff] 


\section{Acknowledgements}

We thank members of the MeadLab for helpful discussions and comments on the manuscript. We thank Dr. Koichi Kawakami for providing the To/2 reagents. We thank Marc Valentine for expert assistance with cytogenetics. We thank the following St. Jude Cancer Center Core Resources for technical support; Hartwell Center for Biotechnology and Bioinformatics for DNA sequencing and bioinformatics support; the Animal Resource Center for assistance with animal husbandry; the Cytogenetics Core Laboratory and the Imaging Core. This study was supported by grants from the $\mathrm{NIH}$ (RO1 HD042294, R01 MH079381 to PEM and RO1 HD046661 to AKS and DEW) and by ALSAC (American Lebanese and Syrian Associated Charities to PEM).

\section{Author details}

'Department of Pathology, St. Jude Children's Research Hospital, 262 Danny Thomas Place, Memphis, TN 38105, USA. ${ }^{2}$ Department of Biology and Biochemistry, University of Houston, Houston, TX 77204, USA.

\section{Authors' contributions}

DAY carried out embryo injections, scored tadpoles, performed molecular analysis of transposon integration sites and helped prepare the manuscript. CMK performed molecular analyses of transposon integration sites, scored tadpoles and helped prepare the manuscript. EK performed embryo injections, scored progeny, assisted with molecular analyses and helped with general husbandry. $\mathrm{HZ}$ performed embryo injections and helped score progeny. AKS and DEW provided mapping data to assign sequence scaffolds to the Xenopus tropicalis linkage groups/chromosomes. PEM conceived the study, directed the project and wrote the manuscript. All authors read and approved the final manuscript.

Received: 22 July 2009

Accepted: 22 January 2010 Published: 22 January 2010

\section{References}

1. Ivics Z, Hackett PB, Plasterk RH, Izsvak Z: Molecular reconstruction of Sleeping Beauty, a Tc1-like transposon from fish, and its transposition in human cells. Cell 1997, 91:501-10.

2. Collier LS, Carlson CM, Ravimohan S, Dupuy AJ, Largaespada DA: Cancer gene discovery in solid tumours using transposon-based somatic mutagenesis in the mouse. Nature 2005, 436:272-6.

3. Keng WW, Villanueva A, Chiang DY, Dupuy AJ, Ryan BJ, Matise I, Silverstein KA, Sarver A, Starr TK, Akagi K, Tessarollo L, Collier LS, Powers S, Lowe SW, Jenkins NA, Copeland NG, Llovet JM, Largaespada DA: A conditional transposon-based insertional mutagenesis screen for genes associated with mouse hepatocellular carcinoma. Nat Biotechnol 2009, 27:264-74

4. Rahrmann EP, Collier LS, Knutson TP, Doyal ME, Kuslak SL, Green LE, Malinowski RL, Roethe L, Akagi K, Waknitz M, Huang W, Largaespada DA, Marker PC: Identification of PDE4D as a proliferation promoting factor in prostate cancer using a Sleeping Beauty transposon-based somatic mutagenesis screen. Cancer Res 2009, 69:4388-97.

5. Starr TK, Allaei R, Silverstein KA, Staggs RA, Sarver AL, Bergemann TL, Gupta M, O'Sullivan MG, Matise I, Dupuy AJ, Collier LS, Powers S, Oberg AL, Asmann YW, Thibodeau SN, Tessarollo L, Copeland NG, Jenkins NA, Cormier RT, Largaespada DA: A transposon-based genetic screen in mice identifies genes altered in colorectal cancer. Science 2009, 323:1747-50.

6. Sinzelle L, Vallin J, Coen L, Chesneau A, Du Pasquier D, Pollet N, Demeneix B, Mazabraud A: Generation of trangenic Xenopus laevis using the Sleeping Beauty transposon system. Transgenic Res 2006, 15:751-60.

7. Doherty JR, Johnson Hamlet MR, Kuliyev E, Mead PE: A flk-1 promoter/ enhancer reporter transgenic Xenopus laevis generated using the Sleeping Beauty transposon system: an in vivo model for vascular studies. Dev Dyn 2007, 236:2808-17.

8. Yergeau DA, Johnson Hamlet MR, Kuliyev E, Zhu H, Doherty JR, Archer TD, Subhawong AP, Valentine MB, Kelley CM, Mead PE: Transgenesis in Xenopus using the Sleeping Beauty transposon system. Dev Dyn 2009, 238:1727-1743.

9. Balciunas D, Davidson AE, Sivasubbu S, Hermanson SB, Welle Z, Ekker SC: Enhancer trapping in zebrafish using the Sleeping Beauty transposon. BMC Genomics 2004, 5:62.

10. Balciunas D, Ekker SC: Trapping fish genes with transposons. Zebrafish 2005, 1:335-41.
11. Davidson AE, Balciunas D, Mohn D, Shaffer J, Hermanson S, Sivasubbu S, Cliff MP, Hackett PB, Ekker SC: Efficient gene delivery and gene expression in zebrafish using the Sleeping Beauty transposon. Dev Biol 2003, 263:191-202.

12. Ogura E, Okuda Y, Kondoh H, Kamachi Y: Adaptation of GAL4 activators for GAL4 enhancer trapping in zebrafish. Dev Dyn 2009, 238:641-55.

13. Sivasubbu S, Balciunas D, Davidson AE, Pickart MA, Hermanson SB, Wangensteen K, Wolbrink DC, Ekker SC: Gene-breaking transposon mutagenesis reveals an essential role for histone H2afza in zebrafish larval development. Mech Dev 2006, 123:513-29.

14. Fraser MJ, Ciszczon T, Elick T, Bauser C: Precise excision of TTAA-specific lepidopteran transposons piggyBac (IFP2) and tagalong (TFP3) from the baculovirus genome in cell lines from two species of Lepidoptera. Insect Mol Biol 1996, 5:141-51.

15. Wu SC, Meir YJ, Coates CJ, Handler AM, Pelczar P, Moisyadi S, Kaminski JM: piggyBac is a flexible and highly active transposon as compared to sleeping beauty, Tol2, and Mos1 in mammalian cells. Proc Natl Acad Sci USA 2006, 103:15008-13.

16. Bonin $\mathrm{CP}$, Mann RS: A piggyBac transposon gene trap for the analysis of gene expression and function in Drosophila. Genetics 2004, 167:1801-11.

17. Hacker U, Nystedt S, Barmchi MP, Horn C, Wimmer EA: piggyBac-based insertional mutagenesis in the presence of stably integrated $\mathrm{P}$ elements in Drosophila. Proc Natl Acad Sci USA 2003, 100:7720-5.

18. Handler AM, Harrell RA: Germline transformation of Drosophila melanogaster with the piggyBac transposon vector. Insect Mol Biol 1999, 8:449-57.

19. Lobo N, Li X, Fraser MJ Jr: Transposition of the piggyBac element in embryos of Drosophila melanogaster, Aedes aegypti and Trichoplusia ni. Mol Gen Genet 1999, 261:803-10.

20. Thibault ST, Singer MA, Miyazaki WY, Milash B, Dompe NA, Singh CM, Buchholz R, Demsky M, Fawcett R, Francis-Lang HL, Ryner L, Cheung LM, Chong A, Erickson C, Fisher WW, Greer K, Hartouni SR, Howie E, Jakkula L, Joo D, Killpack K, Laufer A, Mazzotta J, Smith RD, Stevens LM, Stuber C, LR Tan, Ventura R, Woo A, Zakrajsek I, Zhao L, Chen F, Swimmer C, Kopczynski C, Duyk G, Winberg ML, Margolis J: A complementary transposon tool kit for Drosophila melanogaster using $\mathrm{P}$ and piggyBac. Nat Genet 2004, 36:283-7.

21. Woltjen $K$, Michael IP, Mohseni $P$, Desai R, Mileikovsky M, Hamalainen $R$, Cowling R, Wang W, Liu P, Gertsenstein M, Kaji K, Sung HK, Nagy A: piggyBac transposition reprograms fibroblasts to induced pluripotent stem cells. Nature 2009, 458:766-70

22. Kaji K, Norrby K, Paca A, Mileikovsky M, Mohseni P, Woltjen K: Virus-free induction of pluripotency and subsequent excision of reprogramming factors. Nature 2009, 458:771-5.

23. Hori $H$, Suzuki M, Inagaki $H$, Oshima T, Koga A: An active Ac-like transposable element in teleost fish. Journal Of Marine Biotechnology 1998, 6:206-207.

24. Kawakami K, Shima A: Identification of the Tol2 transposase of the medaka fish Oryzias latipes that catalyzes excision of a nonautonomous Tol2 element in zebrafish Danio rerio. Gene 1999, 240:239-44.

25. Koga A, Suzuki M, Maruyama Y, Tsutsumi M, Hori H: Amino acid sequence of a putative transposase protein of the medaka fish transposable element Tol2 deduced from mRNA nucleotide sequences. FEBS Lett 1999, 461:295-8.

26. Kawakami K, Shima A, Kawakami N: Identification of a functional transposase of the Tol2 element, an Ac-like element from the Japanese medaka fish, and its transposition in the zebrafish germ lineage. Proc Natl Acad Sci USA 2000, 97:11403-8.

27. Kassen SC, Thummel R, Burket CT, Campochiaro LA, Harding MJ, Hyde DR: The $\mathrm{Tg}(\mathrm{ccnb} 1: \mathrm{EGFP})$ transgenic zebrafish line labels proliferating cells during retinal development and regeneration. Mol Vis 2008, 14:951-63.

28. Balciunas D, Wangensteen KJ, Wilber A, Bell J, Geurts A, Sivasubbu S, Wang X, Hackett PB, Largaespada DA, Mclvor RS, Ekker SC: Harnessing a high cargo-capacity transposon for genetic applications in vertebrates. PLoS Genet 2006, 2:e169.

29. Parinov S, Kondrichin I, Korzh V, Emelyanov A: Tol2 transposon-mediated enhancer trap to identify developmentally regulated zebrafish genes in vivo. Dev Dyn 2004, 231:449-59.

30. Nagayoshi S, Hayashi E, Abe G, Osato N, Asakawa K, Urasaki A, Horikawa K, Ikeo K, Takeda H, Kawakami K: Insertional mutagenesis by the Tol2 transposon-mediated enhancer trap approach generated mutations in 
two developmental genes: tcf7 and synembryn-like. Development 2008, 135:159-69.

31. Kawakami K, Takeda H, Kawakami N, Kobayashi M, Matsuda N, Mishina M: A transposon-mediated gene trap approach identifies developmentally regulated genes in zebrafish. Dev Cell 2004, 7:133-44.

32. Choo BG, Kondrichin I, Parinov S, Emelyanov A, Go W, Toh WC, Korzh V: Zebrafish transgenic Enhancer TRAP line database (ZETRAP). BMC Dev Biol 2006, 6:5.

33. Johnson Hamlet MR, Yergeau DA, Kuliyev E, Takeda M, Taira M, Kawakami K, Mead PE: Tol2 transposon-mediated transgenesis in Xenopus tropicalis. Genesis 2006, 44:438-45.

34. Yergeau DA, Mead PE: Manipulating the Xenopus genome with transposable elements. Genome Biol 2007, 8(Suppl 1):S11.

35. Urasaki A, Asakawa K, Kawakami K: Efficient transposition of the Tol2 transposable element from a single-copy donor in zebrafish. Proc Natl Acad Sci USA 2008, 105:19827-32.

36. Garcia-Lecea M, Kondrychyn I, Fong SH, Ye ZR, Korzh V: In vivo analysis of choroid plexus morphogenesis in zebrafish. PLoS One 2008, 3:e3090

37. Winata CL, Korzh S, Kondrychyn I, Zheng W, Korzh V, Gong Z: Development of zebrafish swimbladder: The requirement of Hedgehog signaling in specification and organization of the three tissue layers. Dev Biol 2009, 331:222-36.

38. Vasilyev A, Liu Y, Mudumana S, Mangos S, Lam PY, Majumdar A, Zhao J, Poon KL, Kondrychyn I, Korzh V, Drummond IA: Collective cell migration drives morphogenesis of the kidney nephron. PLoS Biol 2009, 7:e9.

39. Keng WW, Ryan BJ, Wangensteen KJ, Baciunas D, Schmedt C, Ekker SC, Largaespada DA: Efficient Transposition of Tol2 in the Mouse Germline. Genetics 2009, 183:1565-73.

40. Greenblatt IM: A Chromosome Replication Pattern Deduced from Pericarp Phenotypes Resulting from Movements of the Transposable Element, Modulator, in Maize. Genetics 1984, 108:471-485.

41. Chen J, Greenblatt IM, Dellaporta SL: Molecular analysis of Ac transposition and DNA replication. Genetics 1992, 130:665-76.

42. Charlesworth B, Sniegowski P, Stephan W: The evolutionary dynamics of repetitive DNA in eukaryotes. Nature 1994, 371:215-20.

43. Yergeau DA, Kuliyev E, Mead PE: Injection-mediated transposon transgenesis in Xenopus tropicalis and the identification of integration sites by modified extension primer tag selection (EPTS) linker-mediated PCR. Nat Protoc 2007, 2:2975-86.

44. Khokha MK, Krylov V, Reilly MJ, Gall JG, Bhattacharya D, Cheung CY, Kaufman S, Lam DK, Macha J, Ngo C, Prakash N, Schmidt P, Tlapakova T, Trivedi T, Tumova L, Abu-Daya A, Geach T, Vendrell E, Ironfield H, Sinzelle L, Sater AK, Wells DE, Harland RM, Zimmerman LB: Rapid gynogenetic mapping of Xenopus tropicalis mutations to chromosomes. Dev Dyn 2009, 238:1398-46.

45. Groves MR, Barford D: Topological characteristics of helical repeat proteins. Curr Opin Struct Biol 1999, 9:383-9.

46. Sive HL, Grainger RM, Harland RM: Early development of Xenopus laevis. A Laboratory Manual. Cold Spring Harbor, NY: Cold Spring Harbor Laboratory Press 2000.

47. Vignali R, Poggi L, Madeddu F, Barsacchi G: HNF1(beta) is required for mesoderm induction in the Xenopus embryo. Development 2000, 127:1455-65.

48. Christensen KE, Mackenzie RE: Mitochondrial methylenetetrahydrofolate dehydrogenase, methenyltetrahydrofolate cyclohydrolase, and formyltetrahydrofolate synthetases. Vitam Horm 2008, 79:393-410.

49. Krajinovic M: MTHFD1 gene: role in disease susceptibility and pharmacogenetics. Pharmacogenomics 2008, 9:829-32.

50. Jackson TR, Kearns BG, Theibert AB: Cytohesins and centaurins: mediators of PI 3-kinase-regulated Arf signaling. Trends Biochem Sci 2000, 25:489-95.

51. DeMarco R, Venancio TM, Verjovski-Almeida S: SmTRC1, a novel Schistosoma mansoni DNA transposon, discloses new families of animal and fungi transposons belonging to the CACTA superfamily. BMC Evol Biol 2006, 6:89

52. Luo G, Ivics Z, Izsvak Z, Bradley A: Chromosomal transposition of a Tc1/ mariner-like element in mouse embryonic stem cells. Proc Natl Acad Sci USA 1998, 95:10769-73.

53. Fischer SE, Wienholds E, Plasterk RH: Regulated transposition of a fish transposon in the mouse germ line. Proc Natl Acad Sci USA 2001, 98:6759-64.
54. Carlson CM, Dupuy AJ, Fritz S, Roberg-Perez KJ, Fletcher CF, Largaespada DA: Transposon mutagenesis of the mouse germline. Genetics 2003, 165:243-56.

55. Horie K, Yusa K, Yae K, Odajima J, Fischer SE, Keng WW, Hayakawa T, Mizuno S, Kondoh G, ljiri T, Matsuda Y, Plasterk RH, Takeda J: Characterization of Sleeping Beauty transposition and its application to genetic screening in mice. Mol Cell Biol 2003, 23:9189-207.

56. Kondrychyn I, Garcia-Lecea M, Emelyanov A, Parinov S, Korzh V: Genomewide analysis of Tol2 transposon reintegration in zebrafish. BMC Genomics 2009, 10:418.

57. Nieuwkoop PD, Faber F: Normal Table of Xenopus laevis (Daudin). A systematical and chronological survey of the development from the fertilized egg till the end of metamorphosis. New York \& London: Garland Publishing, Inc 1994.

58. Kawakami K, Imanaka K, Itoh M, Taira M: Excision of the Tol2 transposable element of the medaka fish Oryzias latipes in Xenopus laevis and Xenopus tropicalis. Gene 2004, 338:93-8.

59. Weisz PB: The development and morphology of the larva of the South African clawed toad, Xenopus laevis. I. The third-form tadpole. Journal of Morphology 1945, 77:163-192.

doi:10.1186/1471-213X-10-11

Cite this article as: Yergeau et al:: Remobilization of Tol2 transposons in Xenopus tropicalis. BMC Developmental Biology 2010 10:11.

\section{Submit your next manuscript to BioMed Central and take full advantage of:}

- Convenient online submission

- Thorough peer review

- No space constraints or color figure charges

- Immediate publication on acceptance

- Inclusion in PubMed, CAS, Scopus and Google Scholar

- Research which is freely available for redistribution

Submit your manuscript at www.biomedcentral.com/submit
C Biomed Central 